\title{
Salt frost attack on concrete: the combined effect of cryogenic suction and chloride binding on ice formation
}

\author{
Matthias Müller $\mathbb{B} \cdot$ Horst-Michael Ludwig • Marianne Tange Hasholt $\mathbb{C}$
}

Received: 21 May 2021/Accepted: 20 August 2021/Published online: 9 September 2021

(C) The Author(s) 2021

\begin{abstract}
Scaling of concrete due to salt frost attack is an important durability issue in moderate and cold climates. The actual damage mechanism is still not completely understood. Two recent damage theories-the glue spall theory and the cryogenic suction theory-offer plausible, but conflicting explanations for the salt frost scaling mechanism. The present study deals with the cryogenic suction theory, which assumes that freezing concrete can take up unfrozen brine from a partly frozen deicing solution during salt frost attack. According to the model hypothesis, the resulting saturation of the concrete surface layer intensifies the ice formation in this layer and causes salt frost scaling. In this study an experimental technique was developed that makes it possible to quantify to which extent brine uptake can increase ice formation in hardened cement paste (used as a model material for concrete). The experiments were carried out with low temperature differential scanning calorimetry, where specimens were subjected to freeze-thaw cycles while being in contact with $\mathrm{NaCl}$
\end{abstract}

M. Müller $(\bowtie) \cdot$ H.-M. Ludwig

F. A. Finger-Institute for Building Materials Science,

Bauhaus-Universität Weimar, Coudraystr. 11,

99421 Weimar, Germany

e-mail: matthias.mueller@uni-weimar.de

\section{T. Hasholt}

Department Civil Engineering, Technical University of Denmark, Brovej, Building 118, 2800 Kgs Lyngby, Denmark brine. Results showed that the ice content in the specimens increased with subsequent freeze-thaw cycles due to the brine uptake at temperatures below $0{ }^{\circ} \mathrm{C}$. The ability of the hardened cement paste to bind chlorides from the absorbed brine at the same time affected the freezing/melting behavior of the pore solution and the magnitude of the ice content.

Keywords Salt frost attack $\cdot$ Concrete $\cdot$ Cryogenic suction - Chloride binding - Low temperature differential scanning calorimetry $\cdot$ Scaling

\section{Introduction}

Salt frost attack on concrete has been a research topic for many decades. Though many characteristics of this attack are generally acknowledged [1], there is still no consensus on the actual mechanism. Two important characteristics are, that (a) salt frost attack causes scaling (in contrast to frost attack, where the concrete is in contact with pure water) and that (b) most intensive scaling in freeze-thaw tests occurs at moderate de-icer concentrations, e.g. at $3 \mathrm{wt} \% \mathrm{NaCl}$ [2].

An overview on salt frost scaling theories was given in [3]. There it was concluded that only two existing theories have the potential to describe the salt frost scaling mechanism under consideration of all relevant 
characteristics of the attack. However, these theories - the glue spall theory and the cryogenic suction theory-follow conflicting approaches.

The glue spall theory from Valenza and Scherer [4] attributes surface scaling to the interaction of an external ice layer with the concrete surface. Differences in the thermal contraction of ice and concrete generate stresses at the ice-concrete interface at temperatures below $0{ }^{\circ} \mathrm{C}$. A moderate amount of deicing salt in the frozen solution weakens the ice layer, which is consequently more prone to cracking. The cracks propagate into the concrete surface and induce scaling [4]. Some aspects of the glue spall theory were experimentally confirmed, e.g. the increased scaling intensity for thicker ice layers on concrete [5-7]. However, a direct proof of the crack propagation from the ice into the concrete surface has not been published so far.

This paper deals with the cryogenic suction mechanism, which is based on a theory from Lindmark [8], who combined the mechanism of the micro ice body growth [9] with aspects of the frost heaving of soils [10], thus considering the uptake of deicing salt solution in concrete at temperatures below $0{ }^{\circ} \mathrm{C}$. The theory was later extended by Liu and Hansen [11], who referred to it as "the cryogenic suction mechanism".

Two important freezing processes are considered in the theory:

(1) The freezing of pore solution in the concrete. During the freezing process ice lenses in the concrete are firstly formed in capillary pores and in air voids, while the pore solution in gel pores or very fine capillaries remains liquid. The liquid pore solution is drawn towards the ice lenses, where it freezes. This process proceeds until a thermodynamic equilibrium is reached between the ice lenses and the surrounding pore solution [9]. This process is commonly called "cryogenic suction" [11] or "cryosuction" [12].

(2) The eutectic freezing behavior of salt solutions. When a saline solution freezes pure ice crystals begin to form, as the solute does not enter the crystal lattice. The salt concentration in the remaining unfrozen solution (often referred to as "brine") increases while its freezing point decreases. As long as the temperature stays above the eutectic temperature of the deicing solution, the ice contains pockets of non-frozen brine [4].

The innovative approach of Lindmark's theory is the consideration of the non-frozen brine in an external ice layer on concrete as an additional moisture reservoir. When cryogenic suction occurs at temperatures below $0{ }^{\circ} \mathrm{C}$, the ice lenses near the concrete surface do not only attract unfrozen pore solution from the surrounding gel pores, they also attract the liquid brine from the outer ice layer. This allows a continuous growth of surface near ice lenses and consequently causes scaling [8]. In contrast, Liu and Hansen attributed the scaling to stresses, which are caused by the expansion of the saturated surface layer during freezing, while the bulk concrete is shrinking [11, 13].

According to Lindmark's theory the pessimal deicer concentration of $3 \mathrm{wt} \% \mathrm{NaCl}$ in salt frost scaling tests can be explained as follows: on one hand, a minimum salt concentration is necessary to ensure the presence of liquid brine during the frost action. On the other hand, a very high salt concentration is meant to reduce the ice formation and thus to weaken the damage processes [8].

Only few experimental evidences exist for the proposed damage mechanism. Lindmark evaluated the brine uptake due to cryogenic suction by registering mass changes of pre-saturated mortar samples, which were stored in cooled brine at temperatures below $0{ }^{\circ} \mathrm{C}$. He was able to show that the samples gained mass due to the uptake of cooled brine [8]. He attributed this at least partly to the cryogenic suction by the ice lenses and regarded these results as a proof for his theory. Liu and Hansen later used low temperature dilatometry to show, that the brine absorption can indeed cause an expansion of the affected concrete [11]. However, it remains uncertain, whether the brine uptake can actually enable the ice lenses in the surface layer of concrete to grow, as the intruding brine also transports a high amount of dissolved salt ions into the concrete. Consequently, the brine should only be able to contribute to an additional ice formation, if intruding chloride ions are bound in the hardened cement paste (HCP) to some extent.

The effect of highly concentrated NaCl-brine on the ice formation in HCP was therefore investigated in this study using low temperature differential scanning calorimetry (LTDSC). This method can quantify the ice mass in hardened cement paste as a function of 
temperature. LTDSC was applied here in a specific setup, which allowed the cyclic freezing and thawing of hardened cement paste in contact with brine.

\section{Experimental}

\subsection{Materials and specimen preparation}

For the present study three different cements were used-ordinary portland cement (OPC), Portland Limestone Cement (PLC) and Cement with Ground Granulated Blast Furnace Slag (GGBFSC). The OPC was used as reference cement. The other two cements represent typical binders with reduced clinker content, which might show a different behavior during saltfrost action than the OPC.

Data regarding the cements are given in Table 1. The specific surface area was measure with the BLAINE method acc. to DIN EN 196-6:2010-05. The compressive strength was determined on standard mortar acc. to DIN EN 196-1:2016-11.

The mineralogical composition was obtained by quantitative X-Ray diffraction. $20 \mathrm{wt} \%$ Rutile were used as internal standard for measuring the GGBFSC, the other cements required no internal standard.
Siemens/Bruker D5000 $\Theta / 2 \Theta$-instrument with a CuKa-tube operating at $40 \mathrm{~mA}$ and $40 \mathrm{kV}$ was used. The scans were conducted over a range from $6^{\circ}$ to $70^{\circ}$ $2 \Theta$ with a step size of $0.03^{\circ} 2 \Theta$ and a counting time per step of $5 \mathrm{~s}$. The identification of mineral phases and the quantification with Rietveld refinement was carried out with the Open Source software Profex [14].

The investigations were carried out on samples of hardened cement paste. Fresh cement pastes were produced with w/c-ratios of $0.40,0.50$ and 0.60 , using the three different cements and deionized water. The choice of the cement types and w/c-ratios was intended to ensure a broad variation in the capillary pore structure of the HCP samples.

The fresh pastes were filled in $50 \mathrm{ml}$ test tubes (Ø30 $\mathrm{mm})$, which were sealed airtight. The tubes were slowly rotated for four hours to avoid segregation of the solids. Afterwards the tubes were stored in water saturated atmosphere at $20{ }^{\circ} \mathrm{C}$. At an age of one week, discs of HCP with thickness of 1-1.5 mm were cut. The discs were stored in saturated calcium hydroxide solution until the beginning of the measurements at the age of about 28 days. The specimens for LTDSC were not allowed to dry during the preparation procedure. The rest of the HCP samples were stored in a similar

Table 1 Cement properties

\begin{tabular}{llll}
\hline Designation & CEM I 42.5 R & CEM III/A 42.5 N & CEM II/B-LL 32.5 R \\
\hline Type & $\begin{array}{c}\text { Ordinary } \\
\text { Portland } \\
\text { Cement }\end{array}$ & $\begin{array}{c}\text { Cement with } \sim \text { 46 wt\% Ground } \\
\text { Granulated Blast Furnace Slag }\end{array}$ & $\begin{array}{l}\text { Portland Limestone Cement } \\
\text { with } \sim 26 \text { wt\% limestone powder }\end{array}$ \\
& OPC & GGBFSC & PLC \\
Abbreviation & 39.4 & 17.4 & 27.7 \\
Compressive Strength 2d (MPa) & 55.3 & 40.9 \\
Compressive Strength 28d (MPa) & 55.2 & 5120 & 4960 \\
Specific Surface Area (BLAINE) & 4240 & & \\
(cm ${ }^{2} / g$ ) & & & 49.8 \\
Mineralogical Composition (wt\%) & & 35.0 & 5.9 \\
Alite & 69.9 & 3.0 & 7.6 \\
Belite & 6.9 & 4.7 & 2.7 \\
$\mathrm{C}_{3} \mathrm{~A}$ & 10.2 & 1.7 & - \\
$\mathrm{C}_{4} \mathrm{AF}$ & 3.9 & 46.3 & 26.2 \\
Amorphous & - & 2.1 & 7.9 \\
Calcite & 2.8 & 7.4 & \\
Others (Setting Agents, Free & 6.3 & & \\
Lime Periclase, Quartz, etc) & & & \\
\hline
\end{tabular}


manner to be used for mercury intrusion porosimetry (MIP).

$\mathrm{NaCl}$ solution (brine) with a concentration of 22.4 $\mathrm{wt} \% \mathrm{NaCl}$ was used as test solution in the experiments. The solution was prepared by mixing $224.0 \mathrm{~g} \mathrm{NaCl}$ ( $\geq 99.5 \%$ p.a.) with $776.0 \mathrm{~g}$ deionized water. 22.4 $\mathrm{wt} \% \mathrm{NaCl}$ corresponds to the liquidus concentration of $\mathrm{NaCl}$ solutions at $-20{ }^{\circ} \mathrm{C}$ (Fig. 1). All experiments involving the brine were conducted with a target minimum temperature of $-20{ }^{\circ} \mathrm{C}$. Consequently, the brine should remain in liquid state during these experiments, as long as its composition remains unchanged.

\subsection{Pore structure characterization of $\mathrm{HCP}$}

The pore structure of the different HCP compositions was analyzed by MIP. The HCP samples were dried at an age of 28 days using the solvent exchange method. Therefore, small pieces of 2-3 mm were obtained from the HCP. The pieces were stored in isopropanol for one hour and subsequently dried at $40{ }^{\circ} \mathrm{C}$. The samples were then stored in a desiccator until the measurement. The analysis was carried out in a pressure range from 0.003 to $206 \mathrm{MPa}$ in an incremental mode, with a waiting time of $10 \mathrm{~s}$ between the pressure steps. The intrusion pressure was converted into pore entry radius using the Washburn-equation [16] for cylindrical pores. A surface tension of $0.485 \mathrm{~N} / \mathrm{m}$ and a contact angle on the sample surface of $141.3^{\circ}$ were considered for the calculation. The first two pressure steps up to $0.014 \mathrm{MPa}$ were not used for the interpretation, as the mercury intrusion in that

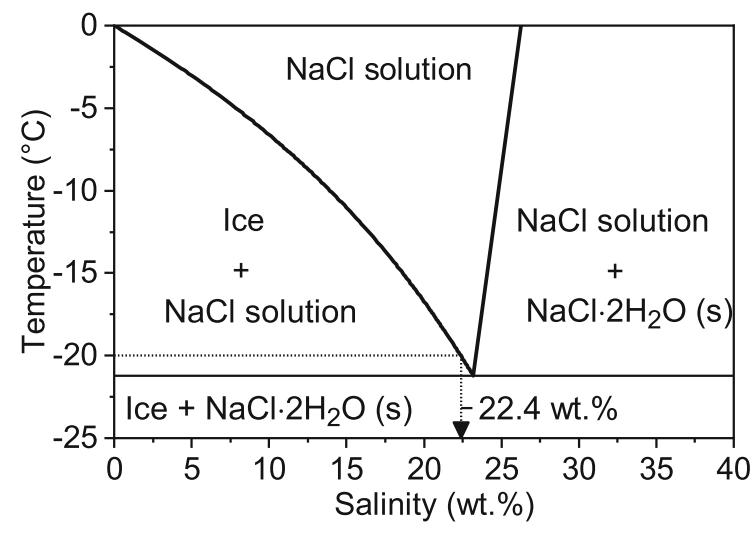

Fig. 1 Binary $\mathrm{H}_{2} \mathrm{O}-\mathrm{NaCl}$ phase diagram, calculated after [15], including $\mathrm{NaCl}$ solution concentration at $-20^{\circ} \mathrm{C}$ pressure range mainly occurred in preparation-related microcracks.

The pore structure was also evaluated by determining the freezing behavior of the pore solution in saturated HCP with LTDSC (without brine). These measurements allowed a characterization of the pore structure with regard to pore size and connectivity, following a classification from Sant et al. [17]. The experiments were conducted at a specimen age of $\sim 28$ days with a Netzsch Differential Scanning Calorimeter (DSC 214 Polyma) in combination with an intercooler, which can realize a minimum temperature of $-70{ }^{\circ} \mathrm{C}$. A small sample of approximately $3 \times 3 \mathrm{~mm}^{2}$ was obtained from each HCP disc. The HCP sample was surface dried with a paper towel and inserted into an aluminum crucible, which was then sealed. The measurements were conducted in the temperature range from +20 to $-60{ }^{\circ} \mathrm{C}$. To avoid supercooling, a procedure following [18] was applied. The samples were cooled to a certain temperature that ensured the formation of ice in the sample, e.g. $-30{ }^{\circ} \mathrm{C}$. The necessary minimum temperature depended on the HCP composition. The samples were then heated to a temperature just below the freezing point of the bulk pore solution, in most cases $-0.3{ }^{\circ} \mathrm{C}$. This temperature was kept constant for $20 \mathrm{~min}$ to equilibrate the sample while still retaining ice nucleates for the immediate formation of ice upon resumed cooling. The samples were then again cooled with a rate of $0.5 \mathrm{~K} / \mathrm{min}$ to a temperature of $-60{ }^{\circ} \mathrm{C}$, followed by a heating phase up to $+20^{\circ} \mathrm{C}$, also with a rate of $0.5 \mathrm{~K} / \mathrm{min}$. The freezing behavior of the pore solution was evaluated qualitatively.

\subsection{Effect of brine on the ice formation in HCP}

The effect of highly concentrated $\mathrm{NaCl}$ brine on the ice formation in HCP was investigated using LTDSC in a specific setup, which allowed the cyclic freezing and thawing of hardened cement paste in contact with brine. The sample preparation and measuring devices were identical to the description given above. However, after inserting the surface dry HCP sample into the aluminum crucible, a small drop of brine was applied on the sample, see Fig. 2. The lid was then cramped tightly onto the crucible (cold welding). During the procedure the mass of the sample, the brine and the crucible with lid was recorded with an accuracy of $0.01 \mathrm{mg}$. The whole process was carried 


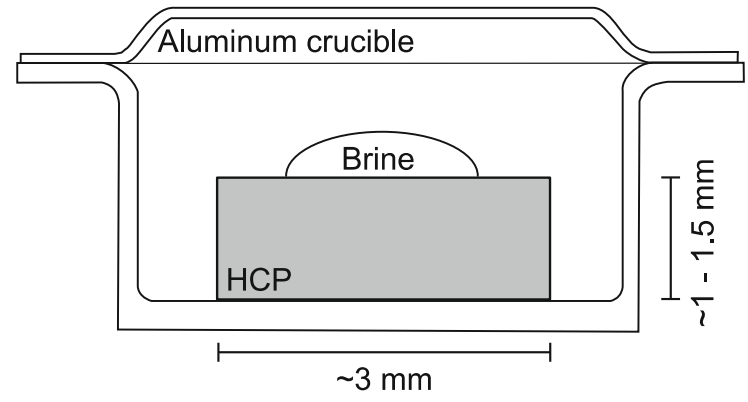

Fig. 2 LTDSC setup- $\mathrm{HCP}$ sample with $\mathrm{NaCl}$ brine on top (schematic)

out in less than one minute to avoid evaporation from the samples. The ratio of HCP to brine was $\sim 20: 1$. Furthermore samples without brine were also prepared for the initial measurement of the ice formation in the HCP without the influence of the brine.

The calorimetric measurements were started immediately after sample preparation. The temperature cycles ranged from $+20{ }^{\circ} \mathrm{C}$ to $-20{ }^{\circ} \mathrm{C}$. The intention behind this test setup was to initiate freezing processes in the hardened cement paste while keeping the brine on the sample in liquid state, hence allowing the uptake of the brine by the cryogenic suction process.

During the cooling phase of the cycles, supercooling of the pore solution in the HCP was observed. Some samples required the additional use of a nucleating agent to achieve ice formation. As reported in $[19,20]$, metaldehyde powder is suitable for that purpose. About 0.1 to $0.2 \mathrm{mg}$ of metaldehyde were given into the DSC crucible before inserting the HCP sample, which was pressed tightly on the powder. However, ice formation was not achieved in the GGBFSC specimen with w/c-ratio of 0.40 , which was therefore excluded from further measurements with this experimental setup.

Figure 3 shows an exemplary temperature cycle in combination with the measured heat flow. Each cycle began with a cooling phase from $+20{ }^{\circ} \mathrm{C}$ to $-20{ }^{\circ} \mathrm{C}$ at $2 \mathrm{~K} / \mathrm{min}$. In the example curve a strong exothermic peak can be observed at $12 \mathrm{~min}$, which denotes the freezing of the supercooled pore solution. The minimum temperature of $-20{ }^{\circ} \mathrm{C}$ was kept constant for $30 \mathrm{~min}$ to allow the cryogenic suction process to take place and to equilibrate the sample. Thereafter the sample was heated to $+20{ }^{\circ} \mathrm{C}$ at $2 \mathrm{~K} / \mathrm{min}$. After an isothermal phase of $1 \mathrm{~min}$ the next cycle was started.
The necessary heat of fusion for melting the frozen pore solution during the heating phase was used to assess the ice volume in the samples. Only one cycle was used for the initial measurement without brine and four subsequent cycles for the samples with brine on top.

The calculation of the normalized heat flow in $\mathrm{mW} /$ $\mathrm{mg}$ required the consideration of the sample mass. Only the mass of the HPC sample was used for the calculation, the mass of the additional brine was neglected. On one hand, this can cause a small error, when the brine contributes to changes in the heat flow. On the other hand to include the mass of the brine would have impaired the comparability to the initial measurement, which was conducted without brine. Consequently, the first approach was adopted and the small error was accepted.

For the quantification of the heat of fusion, a linear baseline was considered to obtain a corrected heat flow curve. Though more complex methods have been reported for calculating baselines in freezing processes [18, 21, 22], this simplified approach was found to be sufficient and more reliable for the relative small temperature range in our experiments. In the temperature range between -20.0 and $-19.5^{\circ} \mathrm{C}$ the heat flow signal showed strong deviations due to the transition from the isothermal phase to the heating phase. This range was excluded from the calculation of the heat of fusion. Quasi-stationary conditions were mostly achieved at approximately $-17.5^{\circ} \mathrm{C}$. However, the deviations in the range between -19.5 and $-17.5^{\circ} \mathrm{C}$ were only small and thus acceptable. At $+5.0^{\circ} \mathrm{C}$ or below the melting process was completed in any measurement. Consequently, only the temperature range from $-19.5^{\circ} \mathrm{C}$ to max. $5.0^{\circ} \mathrm{C}$ was used to calculate the heat of fusion curve by integration of the corrected heat flow signal. This and the following calculations were performed stepwise with a maximum step size below $0.1 \mathrm{~K}$ (Fig. 4).

Subsequently, the heat of fusion divided by the melting enthalpy of water to obtain the mass of ice, that has been melted during the heating phase. Several solutions can be found in literature for the temperature dependence of the melting enthalpy of water. Following recommendations from $\mathrm{Wu}$ et al. [22] the subsequent equation by Randall [23] (taken from [24]) was used, see Eq. (1): 


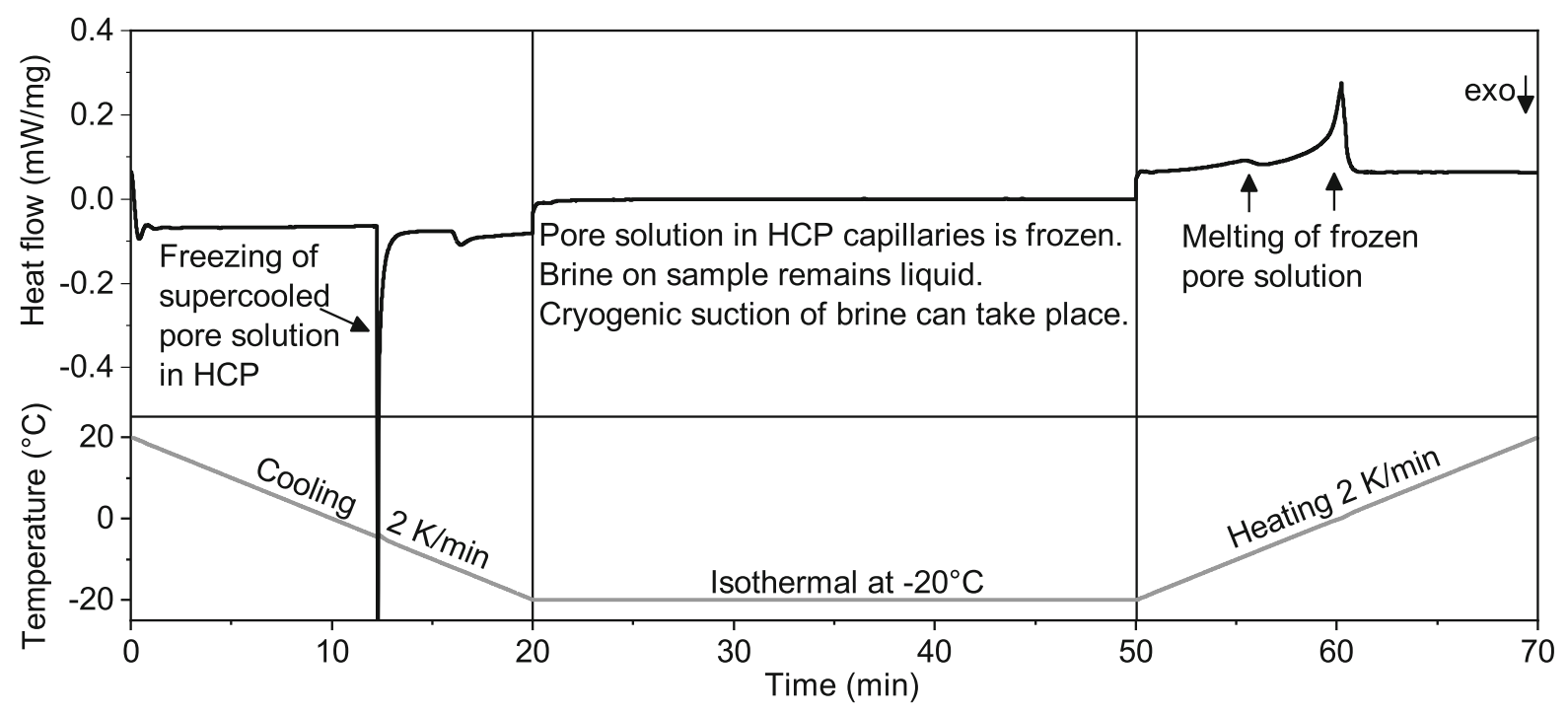

Fig. 3 Exemplary cycle for LTDSC setup $\mathrm{HCP}+\mathrm{NaCl}$ brine

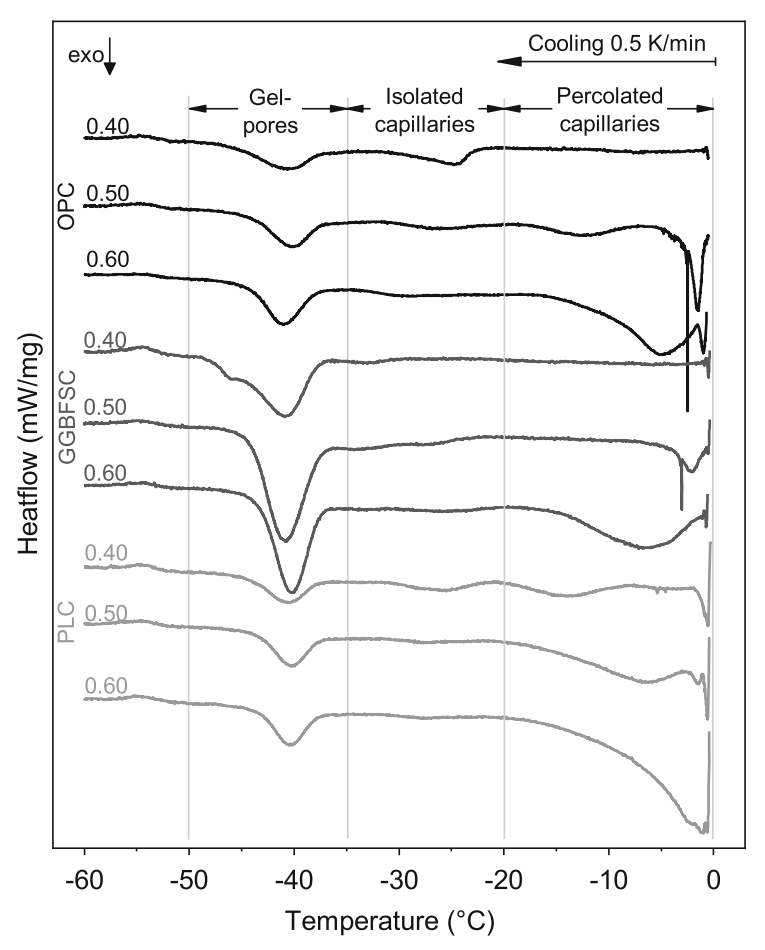

Fig. 4 Freezing curves for different HCP compositions

$$
\begin{aligned}
\Delta H(T)= & 334.1 \\
& +2.119(T-273.15)-0.00873(T-273.15)^{2}
\end{aligned}
$$

where
$-T$ is the temperature in $K$,

$-\Delta H(T)$ the melting enthalpy of water in $\mathrm{J} / \mathrm{g}$.

The melting enthalpy can also be affected by dissolved ions. Wu et al. [22] assumed, that using the melting enthalpy of water is a suitable approximation for pore solution, but they did not consider, whether this is also the case for $\mathrm{NaCl}$ solution. However, according to Mrevlishvili and Privalov [25], the structure of water is only changed to a minor degree by $\mathrm{Na}^{+}$and $\mathrm{Cl}^{-}$ions, so that the influence on the melting enthalpy should also be negligible. The resulting mass of ice represents the mass of freezable water in the experiment.

After completion of each measurement the mass of the crucible including specimen and brine was determined to check, whether the crucibles remained tight during the calorimetric measurements. In neither case did the mass change exceed $0.1 \mathrm{mg}$, so it can be assumed, that no relevant loss of moisture occurred. The lid was then removed from the crucible and the sample was inspected visually to determine, whether the sample surface was still moist or dry.

In the experiment, the addition of the brine can cause a change in the amount of freezable solution in the temperature range to $-20{ }^{\circ} \mathrm{C}$. When chloride ions are bound by the HCP, an increase of freezable solution should occur. This increase is limited by the water content of the brine, which was $77.6 \mathrm{wt} \%$. 


\section{Results and discussion}

\subsection{Characterization of the HCP pore structure}

Table 2 shows the corrected total pore volume and the critical pore radius as measured by MIP. For each cement, the increase of the w/c-ratio led to an increase of the total pore volume. By comparing the different cements it can be seen, that the PLC has a notably higher pore volume than the other two cements.

Notable differences also occurred for the critical pore radius. In the sequence PLC, OPC and GGBFSC and with decreasing $\mathrm{w} / \mathrm{c}$-ratio the critical pore radius is shifted towards smaller radii. Only one result differs from that overall trend. The results confirm the expectations that formed the basis for choosing the different cements and the w/c-ratios.

Figure 4 shows the freezing curves of the hardened cement paste samples. The heat flow is displayed as a function of temperature. Temperature ranges were defined corresponding to typical freezing effects in $\mathrm{HCP}$, roughly following a classification from Sant et al. [17]. The range from 0 to $-20{ }^{\circ} \mathrm{C}$ covers the ice formation in the percolated network of capillary pores, which is induced by heterogeneous nucleation. In the range from -20 to $-35{ }^{\circ} \mathrm{C}$ freezing occurs by heterogeneous nucleation in open gel pores or isolated capillary pores. Below $-35^{\circ} \mathrm{C}$ the ice formation is induced primarily by homogeneous nucleation. This range can be attributed to freezing processes in isolated gel pores.

With regard to durability and salt frost scaling resistance, a high volume of percolated capillaries is detrimental. As expected, the volume of percolated capillaries in the HCP increases for higher w/c-ratios.

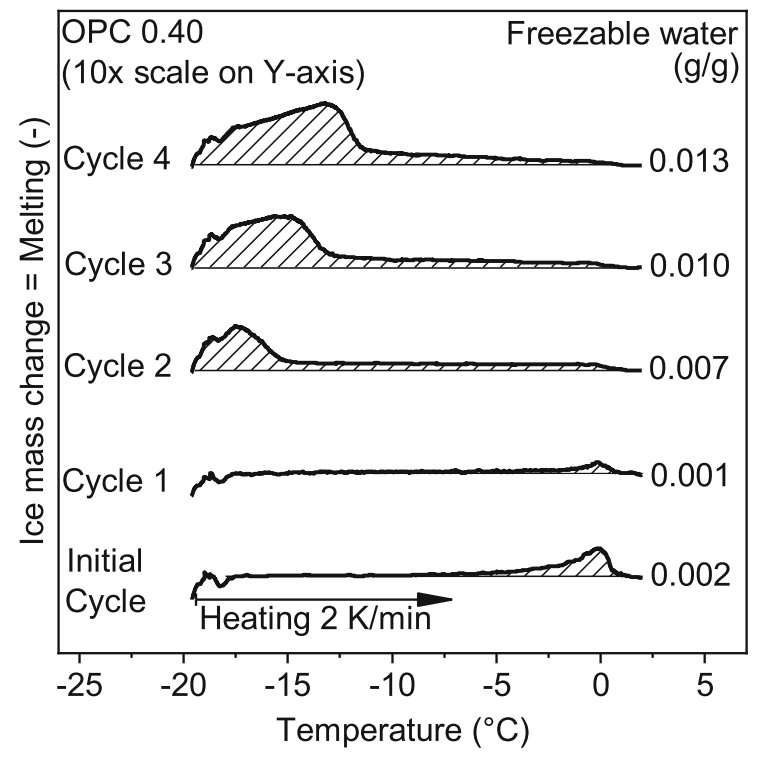

Fig. 5 Melting curves in LTDSC measurements-OPC $w /$ $c=0.40$

Following characteristics are found for the different cements:

- PLC samples possess the highest volume of percolated capillaries, followed by OPC and GGBFSC

- For a w/c-ratio of 0.40, no freezing peak occurs for OPC and GGBFSC in the range of the percolated capillaries. PLC shows a sharp peak just below $0{ }^{\circ} \mathrm{C}$ and a second broad peak between -10 and $-20{ }^{\circ} \mathrm{C}$.

- For a w/c-ratio of 0.50 , all cements show at least one freezing peak between 0 and $-20{ }^{\circ} \mathrm{C}$. For the GGBFSC only a single peak occurs, whereas a second broad peak can be observed for the other
Table 2 Mercury intrusion porosimetry results

\begin{tabular}{llll}
\hline Cement & $w / c$-Ratio & $\begin{array}{l}\text { Intrusion volume (corrected) } \\
{[\mathrm{ml} / \mathrm{g}]}\end{array}$ & $\begin{array}{l}\text { Critical pore radius } \\
{[\mu \mathrm{m}]}\end{array}$ \\
\hline OPC & 0.40 & 0.111 & 0.047 \\
& 0.50 & 0.168 & 0.048 \\
\multirow{2}{*}{ GGBFS cement } & 0.60 & 0.236 & 0.060 \\
& 0.40 & 0.117 & 0.013 \\
& 0.50 & 0.193 & 0.024 \\
PLC & 0.60 & 0.254 & 0.021 \\
& 0.40 & 0.162 & 0.041 \\
& 0.50 & 0.247 & 0.063 \\
& 0.60 & 0.299 & 0.080 \\
\hline
\end{tabular}


cements. This indicates a bimodal pore entry radius distribution for those cements.

- For a w/c-ratio of 0.60, all cements show distinct freezing effects in the temperature range from 0 to $-20{ }^{\circ} \mathrm{C}$.

The porosity in the range of the isolated capillaries is low in all samples. Notable freezing peaks in this temperature range only occur in the samples with OPC and PLC with a w/c-ratio of 0.40 .

The amount of gel pores is mainly governed by the cement type. GGBFSC shows a notably higher gel porosity. Furthermore the w/c-ratio also affects the gel porosity. A w/c-ratio increase from 0.40 to 0.50 causes an increase of the gel porosity. A further increase to w/c-ratio of 0.60 has no clear effect.

\subsection{Impact of brine on ice formation}

\subsubsection{Freezing onset}

For the interpretation of the subsequent melting curves, it is important to evaluate where the initial ice formation takes place in the experiments. In general, the first formation of ice should occur in the $\mathrm{HCP}$, as the brine should remain liquid due to its high chloride concentration. However, it cannot be ruled out that diffusion processes cause a reduction of the chloride content in the brine, while it is still on top of the specimen. This might cause the initial ice formation to take place outside the specimen in the outer brine. Table 3 shows the freezing onsets for the LTDSC measurements.

\subsubsection{LTDSC melting curves}

The OPC sample with w/c-ratio of 0.40 was chosen as a starting point in the illustration of the results. Figure 5 shows the melting curves of the initial LTDSC cycle without brine and of the four succeeding cycles with brine. The curves are displayed with a vertical offset as a function of the temperature. The decrease of the ice mass is defined as a positive value in this figure. The calculated total of the ice mass is also given for each melting curve. As the ice mass equals the amount of freezable water in the temperature range of the measurements $\left(\geq-20{ }^{\circ} \mathrm{C}\right)$, it is termed as such in the following figures.

Please note that a different scale is used for the melting curves of OPC 0.40 (Fig. 5). As the amount of freezable water is very low in comparison to OPC 0.50 and OPC 0.60, the scale was enhanced by factor 10 to allow a visual assessment of the curves. The small fluctuation at the start of the melting curves $(-19.5$ to $-17.5^{\circ} \mathrm{C}$ ) was caused by the transition from the isothermal phase to the heating phase in the measurement.

The initial measurement reveals a very low amount of freezable water in the specimen, as only very little pore solution is freezable in the range to $-20{ }^{\circ} \mathrm{C}$. A small melting peak with a maximum at about $-1{ }^{\circ} \mathrm{C}$ can be observed. During the first cycle with brine the amount of freezable water decreases even more and the melting peak vanishes almost completely.

In the second cycle with brine a new melting peak occurs in the temperature range directly above $-20{ }^{\circ} \mathrm{C}$. With proceeding freeze-thaw cycles this peak broadens and shifts towards higher temperatures, while the amount of freezable water increases. The
Table 3 Freezing onsets in the LTDSC measurement; (*) indicates use of metaldehyde

\begin{tabular}{lllllll}
\hline Cements & $w / c$-Ratio & \multicolumn{5}{l}{ Freezing onset $\left({ }^{\circ} \mathrm{C}\right)$} \\
\cline { 3 - 7 } & & Initial Cycle & Cycle 1 & Cycle 2 & Cycle 3 & Cycle 4 \\
\hline OPC & 0.40 & $-17.42^{*}$ & $-19.32^{*}$ & $-14.38^{*}$ & $-20.00^{*}$ & $-14.14^{*}$ \\
& 0.50 & -14.57 & $-4.46^{*}$ & $-7.48^{*}$ & $-10.56^{*}$ & $-13.06^{*}$ \\
& 0.60 & -13.83 & -14.22 & -15.11 & -14.62 & -15.48 \\
GGBFSC & 0.40 & - & - & - & - & - \\
& 0.50 & -8.87 & $-15.61^{*}$ & $-14.72^{*}$ & $-14.88^{*}$ & $-16.37^{*}$ \\
& 0.60 & -14.18 & -15.04 & -15.27 & -14.64 & -13.35 \\
PLC & 0.40 & $-7.92 *$ & $-9.78^{*}$ & $-10.94 *$ & $-9.52^{*}$ & $-9.15^{*}$ \\
& 0.50 & -14.86 & $-9.48^{*}$ & $-8.18^{*}$ & $-13.88^{*}$ & $-13.67 *$ \\
& 0.60 & -10.57 & $-3.00^{*}$ & $7.01 *$ & $-8.88^{*}$ & $-7.73^{*}$ \\
\hline
\end{tabular}


surface of the sample was still moist after the measurement. Obviously, the brine was not absorbed completely during the freeze-thaw-cycles.

Different processes might account for the occurrence of the second melting peak:

1. Ice is firstly formed inside the specimen. The resulting cryogenic suction by the ice lenses causes the (partly) uptake of brine. Chloride binding by the HCP can reduce the concentration of free chlorides in the absorbed brine, which consequently is able to (partly) freeze at temperatures above $-20^{\circ} \mathrm{C}$.

2. Other diffusion processes between the brine on top of the specimen and the specimen surface can cause a reduction of the concentration of free chlorides in the brine, while it remains outside the porous structure of the HCP. The high concentration of solutes in the brine should initiate the osmosis of water from the pore solution of the HCP to the brine [8]. Furthermore, a diffusion of chloride ions into the HCP can occur [26], which would also reduce the chloride concentration in the outer brine. Upon cooling, ice is firstly formed inside the specimen and acts as a nucleus for the (partial) freezing of the brine on top of the specimen.

3. Similar to (2.), but with the initial ice formation in the brine.

The freezing onset (Table 3) from the preceding freezing curves gives an indication, whether the initial ice formation occurred in the specimen or in the outer brine. Except for cycle 3, the freezing always occurs at temperatures above $-20{ }^{\circ} \mathrm{C}$, e.g. at $-14.38{ }^{\circ} \mathrm{C}$ in cycle 2 . It is thus rather unlikely that the freezing process starts in the brine. The high chloride concentration (even after some potential chloride binding in the HCP) should prevent ice nucleation in the brine at temperatures $>-20{ }^{\circ} \mathrm{C}$. However, as the specimen surface was still moist after the measurement it remains unclear, whether brine was actually sucked into the HCP.

Figure 6 shows the melting curves for the OPC 0.50 . In the initial measurement, the melting process sets in at about $-6{ }^{\circ} \mathrm{C}$, with a slow rise of the curve. At $-1{ }^{\circ} \mathrm{C}$ the curve shows a steep rise, as the melting process intensifies. At $+0.3{ }^{\circ} \mathrm{C}$ the curve reaches its peak maximum and then declines continuously, until the melting process is complete by $+2{ }^{\circ} \mathrm{C}$. The

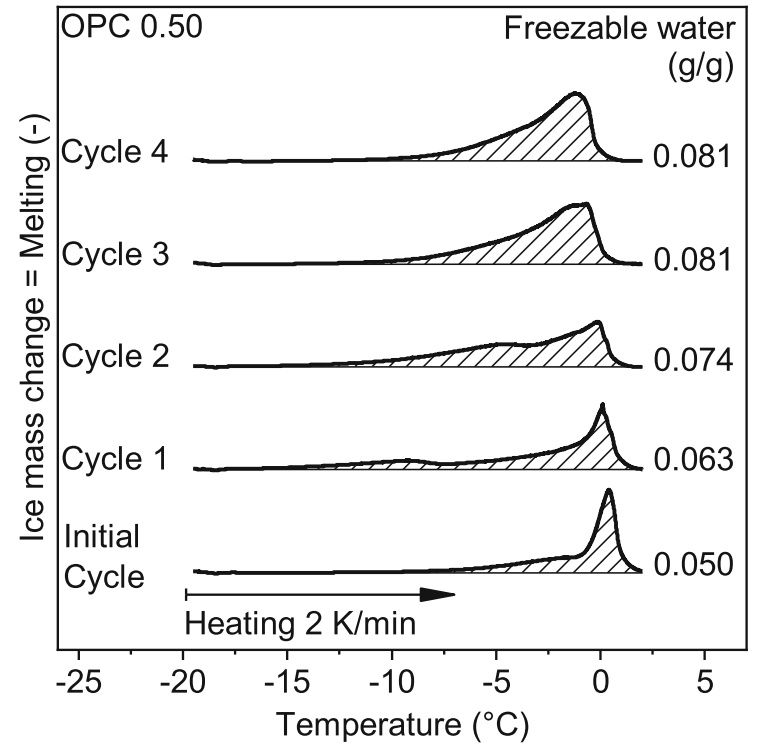

Fig. 6 Melting curves in LTDSC measurements-OPC w/ $c=0.50$

amount of freezable water in the considered temperature range amounts to $0.050 \mathrm{~g} / \mathrm{g}$.

In the melting curve of cycle 1 , which is the first cycle with brine on top of the sample, a second small melting peak occurs at $-10{ }^{\circ} \mathrm{C}$. The peak is very broad and merges with the main peak at $-7^{\circ} \mathrm{C}$. The position of the main peak maximum is shifted slightly towards lower temperatures.

The amount of freezable water increases to $0.063 \mathrm{~g} /$ g. With proceeding cycles both melting peaks merge into one single peak. The amount of freezable water increases up to $0.081 \mathrm{~g} / \mathrm{g}$ in the third cycle and then remains constant. When the crucible was opened after the measurement it was revealed, that the HCP sample was surface dry. A moisture loss during the measurement from the sealed crucible can be ruled out, as no mass loss occurred. The sample itself was intact, but could easily be broken with slight pressure of the tweezers tip.

The observed effects make evident that the brine was taken up by HCP during the freeze-thaw-cycles. Consequently, the freezing and melting temperatures of the original pore solution were decreased due to the blending with the absorbed brine. The increase of the amount of freezable water indicates a binding of chloride ions from the absorbed brine by the HCP.

Figure 7 shows the melting curves for the OPC with w/c-ratio of 0.60 . The performance is quite similar to 


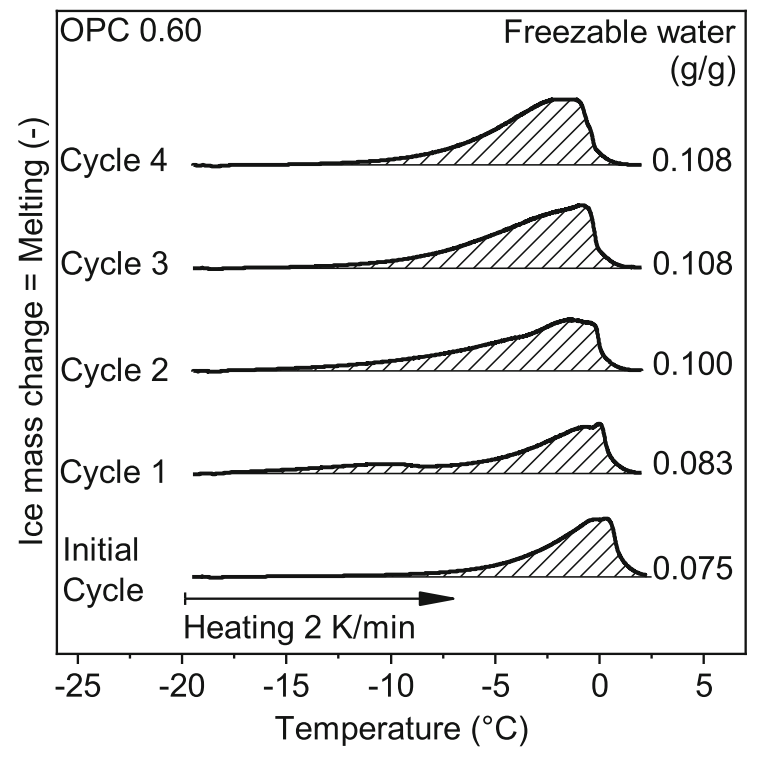

Fig. 7 Melting curves in LTDSC measurements-OPC w/ $c=0.60$

the sample with w/c-ratio of 0.50 . As expected the initial ice volume during the reference cycle is higher in comparison to the samples with lower w/c. However, during the subsequent freeze-thaw cycles the increase in freezable water is comparable to the specimen with $w / c=0.50$.

The detailed results for the other cements are given in Appendix A, as the principal trends of the melting curves are similar to the OPC samples. The changes in the ice mass or rather freezable water in all specimens are compared hereafter.

\subsubsection{Impact of cement type on the changes regarding the amount of freezable water}

Figure 8 gives an overview on the changes of the amount of freezable water due to the freeze-thaw cycles with brine for all HCP samples. Only GGBFSC with w/c-ratio of 0.40 is excluded, as it was not possible to achieve ice formation in that sample. Specimens with incomplete brine uptake are displayed with dashed lines. Two parameters are of special interest in the figure: the initial amount of freezable water and the change of the freezable water amount until cycle 4 .

A high initial content of freezable water implies a large proportion of percolated capillaries in the $\mathrm{HCP}$, which enables intensive transport processes inside and into the HCP matrix. Furthermore, it indicates a higher number of individual ice nuclei that can exert cryogenic suction. Consequently, a more intensive cryogenic suction process in the HCPs with a high initial amount of freezable water can be expected.

Figure 8 reveals a clear impact of the w/c-ratio on the initial amount of freezable water, as higher w/cratios lead to an increased capillary porosity in $\mathrm{HCP}$ or concrete [27]. The cement type also affects the amount freezable water. It increases in the sequence GGBFSC, OPC and PLC. Concrete or HCP with GGBFSC typically has a low capillary porosity, provided a sufficient degree of hydration is reached [28, 29], whereas PLC with a limestone powder content above $10-15 \mathrm{wt} \%$ often has an increased volume of capillary pores [30] in comparison to OPC.

Regarding the changes of the amount of freezable water over the subsequent freeze-thaw cycles, all samples show an increase due to the brine-frost exposure. The results thus confirm the basic assumption of the cryogenic suction theory [8]. In specimens with lowest w/c-ratios in Fig. 8, the brine is only partly absorbed by the HCP. It cannot be ruled out for these specimens that some ice formation occurs in the brine outside the HCP. In the HCP specimens with higher $w /$ $c$-ratio the brine is completely absorbed and consequently the increase in freezable water is more pronounced.

The cement type also affects the magnitude of the increase of freezable water. Provided the initial amount of freezable water is sufficiently high (about $\geq 0.050 \mathrm{~g} / \mathrm{g}$ in our measurements), the increase of the freezable water content for OPC and GGBFSC is comparable. The PLC, in contrast, only shows a small increase, despite its high capillary porosity and high initial freezable water content. It can thus be assumed, that further influences have an effect on the ice volume growth due to the brine uptake, most probably the chloride binding potential of the HCP.

The cement specific influence on the change in freezable water can be further assessed by dividing the measured increase by the potential maximum increase resulting from the actual brine addition (Table 4).

The resulting relative increase of the freezable water content in $\%$ is given in Fig. 9. For a value of $100 \%$ the water content of the brine must completely contribute to the ice formation in the temperature range up $\geq-20^{\circ} \mathrm{C}$. Samples that had a moist 


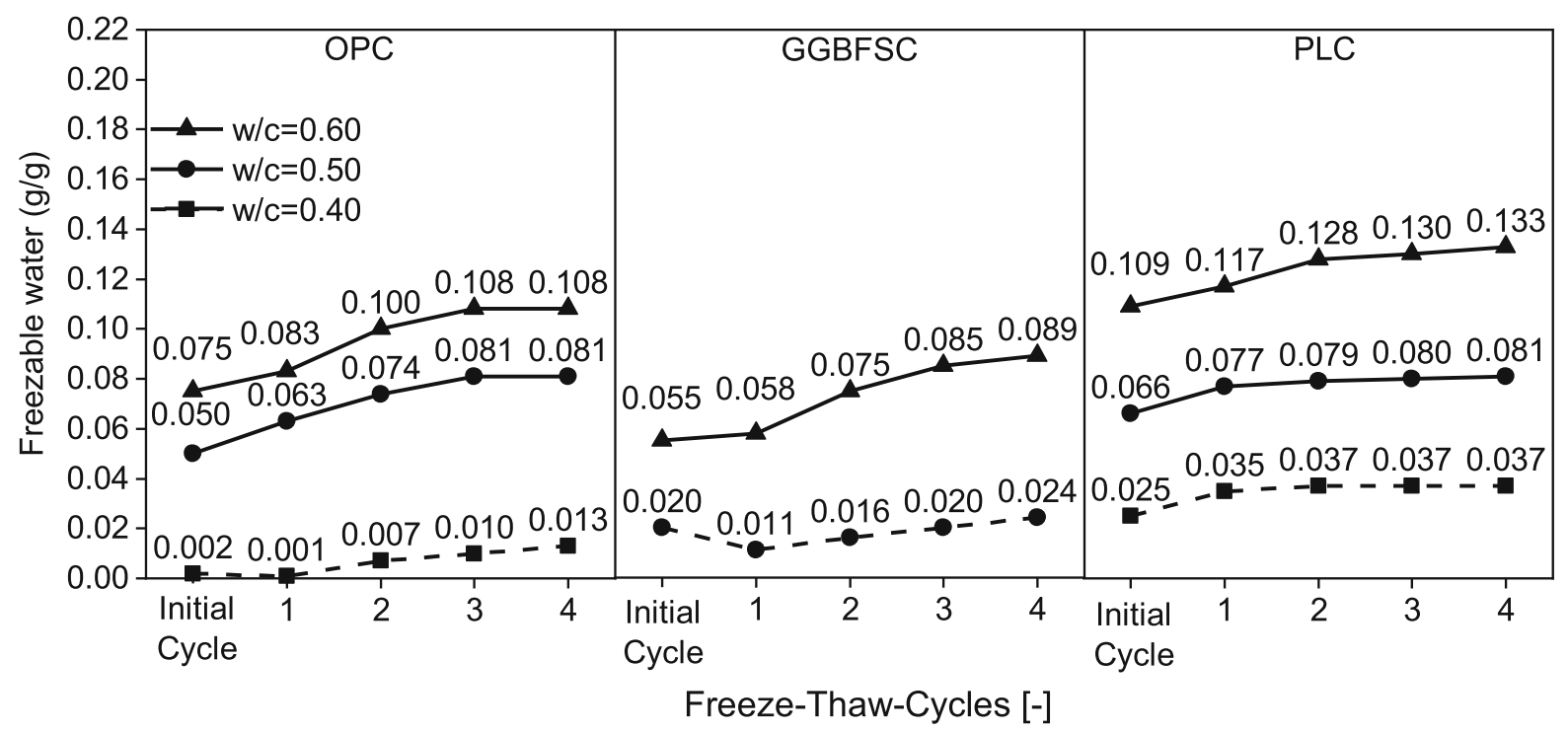

Fig. 8 Change in freezable water content due to cyclic freezing and thawing of HCP and brine. Dashed lines indicate incomplete brine uptake

Table 4 Potential increase in freezable water

\begin{tabular}{llll}
\hline Cement & $w / c$-Ratio & $\begin{array}{l}\text { Brine addition } \\
{[\mathrm{g} \text { per g HCP] }}\end{array}$ & $\begin{array}{l}\text { Amount of water in brine } \\
\text { [g per g HCP] }\end{array}$ \\
\hline OPC & 0.40 & 0.052 & 0.040 \\
& 0.50 & 0.049 & 0.038 \\
& 0.60 & 0.052 & 0.040 \\
GGBFSC & 0.40 & - & - \\
& 0.50 & 0.048 & 0.037 \\
& 0.60 & 0.050 & 0.039 \\
PLC & 0.40 & 0.056 & 0.043 \\
& 0.50 & 0.047 & 0.036 \\
& 0.60 & 0.052 & 0.040 \\
\hline
\end{tabular}

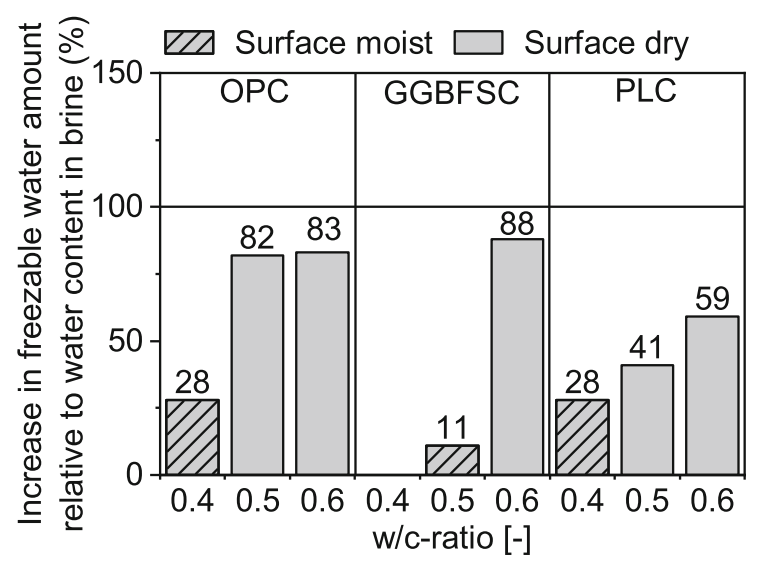

Fig. 9 Increase in amount of freezable water in relation to water content in brine surface after the measurement are labeled as such in the figure.

For the samples that were surface dry after 4 cycles, the relative increase of freezable water reached values of approximately 80-90\% for OPC and GGBFSC, but only $40-60 \%$ for the PLC. A mass loss due to moisture evaporation from the crucible can be excluded.

A potential explanation for the performance of the PLC lies in its relatively low chloride binding potential. Experience from previous research shows that for OPC and for cements with GGBFS a notably higher chloride binding potential than for PLC can be expected [31, 32]. Different processes for the reduction of the chloride concentration in the capillary pore solution after the brine uptake can be considered: 
- Chloride ions can be chemically bound in mineral phases, mainly as Friedel's salt [33]. A high clinker substitution rate $(>10-15 \mathrm{wt} \%)$ with quasi-inert limestone powder reduces the amount of aluminum bearing phases in the HCP, which can bind chlorides in Friedel's salt. However, recent research shows that the contribution of Friedel's salt formation on chloride binding is rather small [34].

- Chloride ions can be physically adsorbed on surfaces in the hardened cement paste. Due to the high specific surface area the adsorption mainly occurs on $\mathrm{C}-\mathrm{S}-\mathrm{H}$-phases $[35,36]$. Whereas clinker substitution with GGBFS increases the amount of $\mathrm{C}-\mathrm{S}-\mathrm{H}-$ phases and thus the chloride binding capacity [37], the incorporation of high amounts of quasi-inert limestone should reduce the $\mathrm{C}-\mathrm{S}-\mathrm{H}$ content.

With regard to the increase of freezable water, it can be concluded that for PLC more chloride ions remain dissolved in the pore solution, thus depressing the freezing and melting point more strongly.

The impact of the chloride binding can be evaluated indirectly by comparing the shift of the melting peak of the pore solution between the initial cycle and cycle 4 with brine. Figure 10 shows those two melting peaks for the different cements. For OPC and PLC the samples with $w / c=0.50$ are displayed. For the GGBFSC the sample with $w / c=0.60$ is shown, as only here a complete uptake of the brine occurred.

A shift of the melting peak maximum towards lower temperatures is observed for all samples. The magnitude of the shift for OPC and GGBFSC is $1.70 \mathrm{~K}$. The PLC shows a shift of $3.65 \mathrm{~K}$. This indicates that indeed more dissolved chloride ions remain in the capillary pore solution of the PLC. Therefore, a higher amount of pore solution should freeze only below $-20^{\circ} \mathrm{C}$.

In our specific test setup the variation of brine to capillary pore solution ratio must also be considered. This variation occurred due to the different contents of capillary pore solution in the HCP. This can be deduced from the differences in the initial amount of freezable water (see Fig. 8). As the sample PLC 0.50 has the highest initial amount of freezable water $(0.066 \mathrm{~g} / \mathrm{g})$ in comparison to OPC $0.50(0.050 \mathrm{~g} / \mathrm{g})$ and the GGBFSC $0.60(0.055 \mathrm{~g} / \mathrm{g})$ from Fig. 10, the ratio of brine to capillary pore solution cannot be the

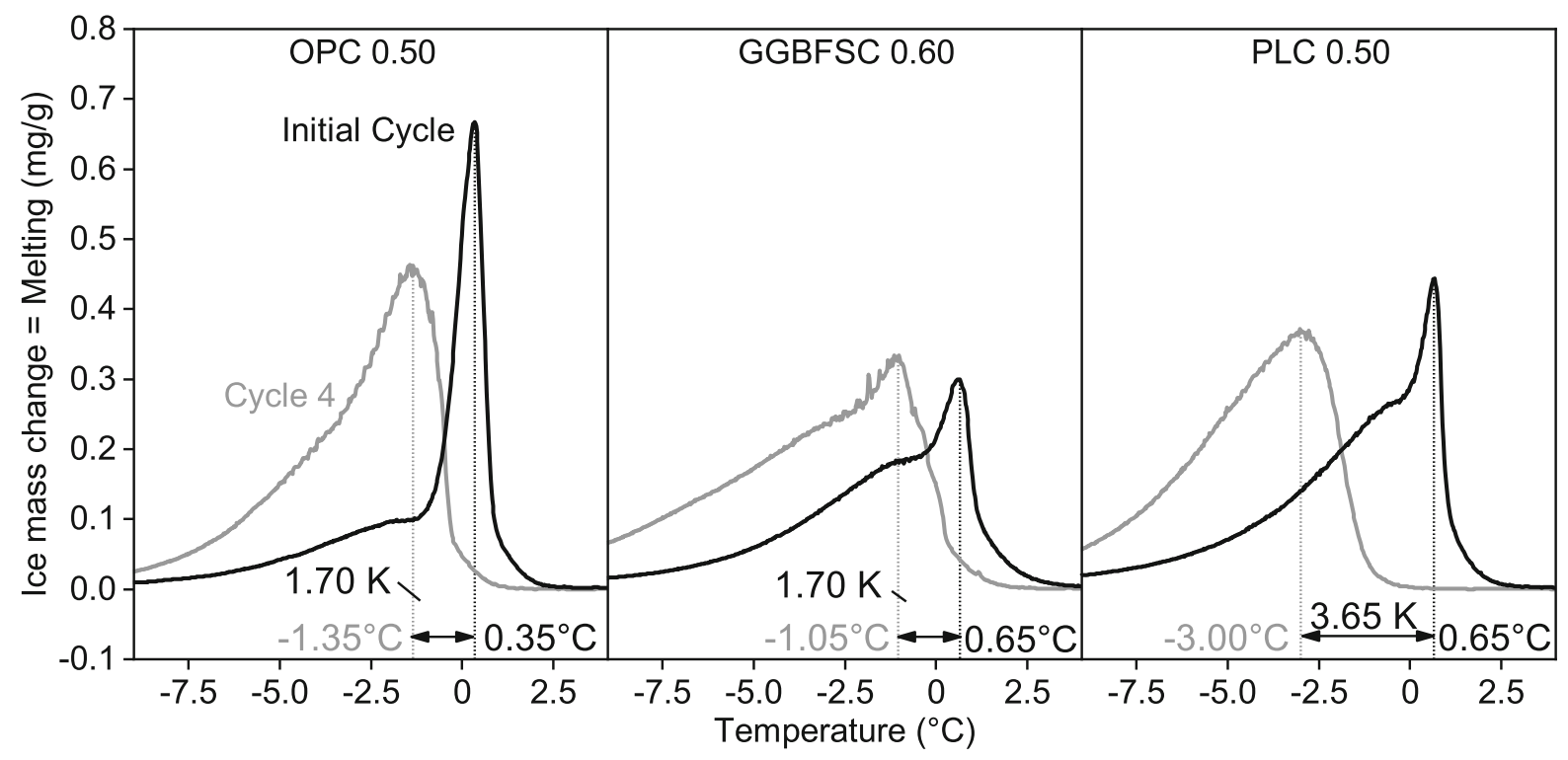

Fig. 10 Comparison of the Peak Maximum of the "Initial Cycle" and "Cycle 4" in the LTDSC measurement of HPC and brine of selected samples 
cause for the strong freezing point depression in the PLC.

The cement specific chloride binding potential is a contributing factor to the ice formation in hardened cement paste due to the uptake of $\mathrm{NaCl}$ brine and thus probably also to the salt frost scaling resistance of concrete. However, in comparison to the importance of the capillary porosity and of the air void structure in concrete, the effect of the chloride binding potential is probably minor.

\section{Conclusions}

The cryogenic suction theory [8] attributes the generation of scaling to the uptake of unfrozen brine by ice lenses in freezing concrete. This additional moisture supply during the frost phase of a salt frost attack should enable further growth of the surface near ice lenses in concrete and thus cause scaling.

The proposed damage process was investigated using a special low temperature differential scanning calorimetry setup, in which saturated hardened cement paste (HCP) was subjected to freeze-thaw cycles while being in contact with $\mathrm{NaCl}$ brine $(22.4 \mathrm{wt} \%)$. With this setup, it was possible to directly evaluate the impact of brine on the ice formation in the HCP during freeze-thaw exposure.

It was found that freezing HCP indeed takes up brine during the freeze-thaw cycles and that this uptake causes an increase of the amount of freezable water in the HCP. The main damage process described by the cryogenic suction theory was confirmed.

The increase of the amount of freezable water was governed by the capillary porosity and by the chloride binding capacity of the HCP. Percolated capillaries enhance the moisture transport into the HCP. An intensive brine uptake thus occurred mainly in HCP with a high volume of percolated capillaries. The binding of chlorides from the uptaken brine is necessary to diminish the chemical freezing point depression. The maximum increase for the amount of freezable water was thus determined on HCP with a high chloride binding potential.

Authors' contributions Matthias Müller: Conceptualization, Methodology, Investigation, Formal Analysis, Writingoriginal draft, Visualization. Horst-Michael Ludwig: Writing-review \& editing, Supervision, Project administration, Resources. Marianne Tange Hasholt: Writing-review \& editing.

Funding Open Access funding enabled and organized by Projekt DEAL. The research was supported by the Deutsche Forschungsgemeinschaft (DFG) under Grant LU1652/29-1.

\section{Declarations}

Conflict of interest The authors declare that they have no conflict of interest.

Open Access This article is licensed under a Creative Commons Attribution 4.0 International License, which permits use, sharing, adaptation, distribution and reproduction in any medium or format, as long as you give appropriate credit to the original author(s) and the source, provide a link to the Creative Commons licence, and indicate if changes were made. The images or other third party material in this article are included in the article's Creative Commons licence, unless indicated otherwise in a credit line to the material. If material is not included in the article's Creative Commons licence and your intended use is not permitted by statutory regulation or exceeds the permitted use, you will need to obtain permission directly from the copyright holder. To view a copy of this licence, visit http://creativecommons.org/licenses/by/4.0/.

\section{Appendix A}

See Appendix Figs. 11, 12, 13, 14 and 15. 


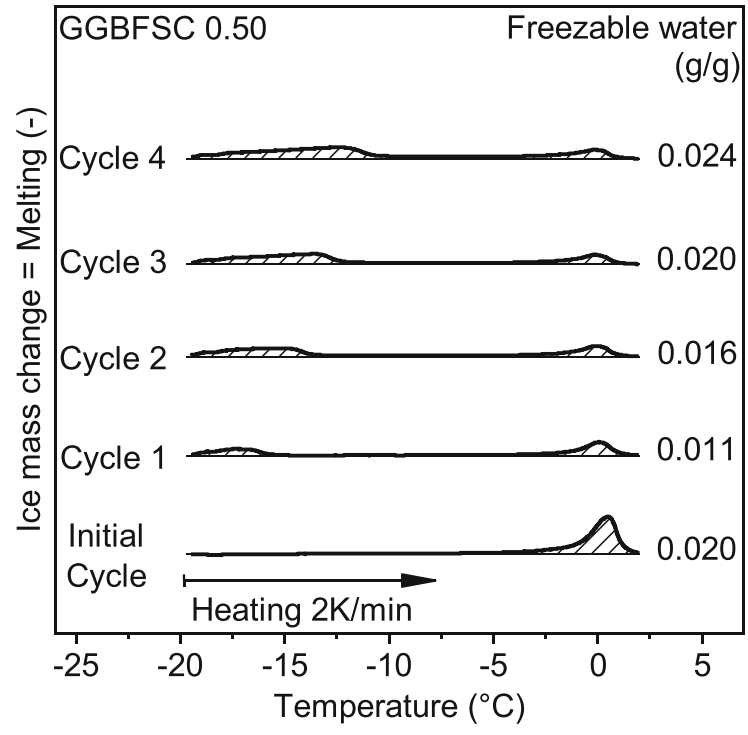

Fig. 11 Melting curves in LTDSC measurements-GGBFSC $w / c=0.50$

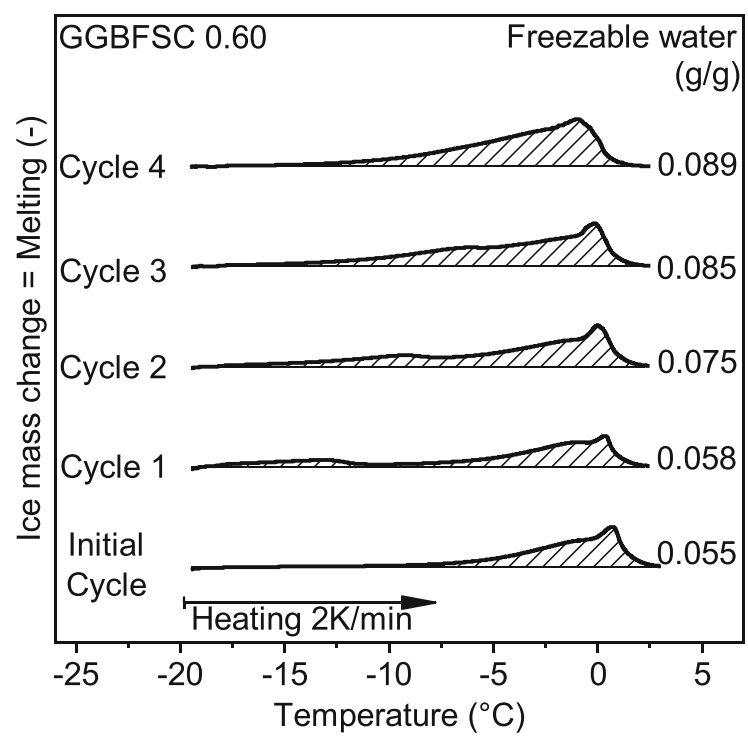

Fig. 12 Melting curves in LTDSC measurements-GGBFSC $w / c=0.60$

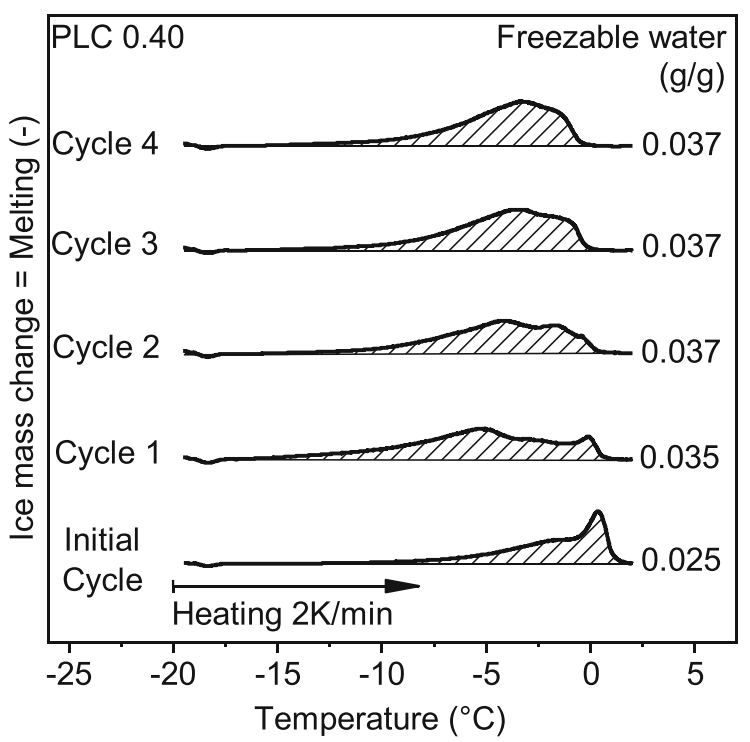

Fig. 13 Melting curves in LTDSC measurements-PLC $w /$ $c=0.40$

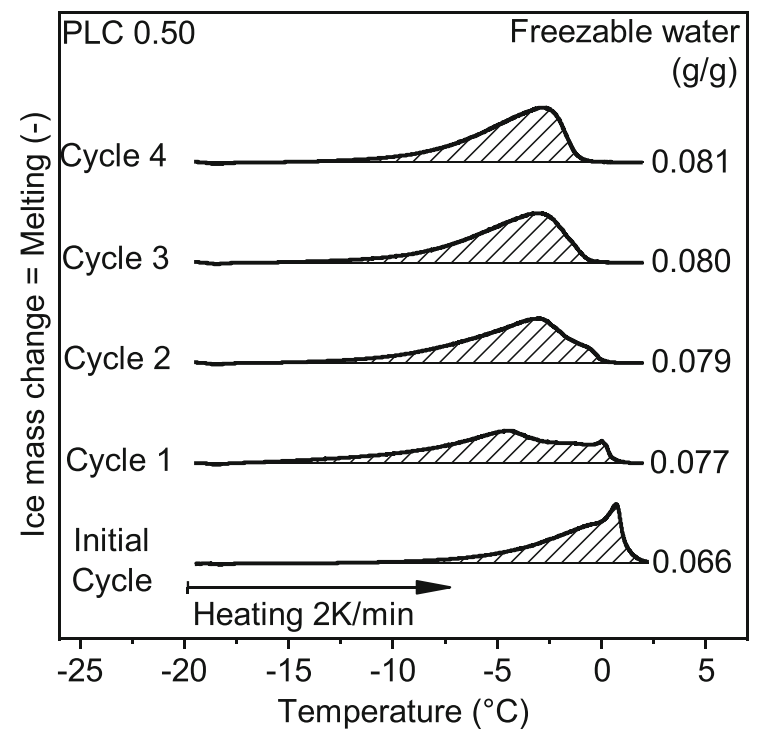

Fig. 14 Melting curves in LTDSC measurements-PLC $w /$ $c=0.50$ 
Fig. 15 Melting curves in LTDSC measurements$\mathrm{PLC} w / c=0.60$

\section{References}

1. Valenza JJ II, Scherer GW (2007) A review of salt scaling: I. Phenomenol Cem Concrete Res 37(7):1007-1021. https:// doi.org/10.1016/j.cemconres.2007.03.005

2. Verbeck GJ, Klieger P (1956) Studies of "salt" scaling of concrete. Highw Res Board Bull 150:1-13

3. Müller M, Ludwig HM, Ehrhardt D (2019) Frost-TausalzAngriff aus Beton-mechanismen und schadensmodelle. Beton-Stahlbetonbau 114(6):392-400. https://doi.org/10. 1002/best.201800096

4. Valenza JJ II, Scherer GW (2007) Mechanism for salt scaling of a cementitious surface. Mater Struct/Mater Constr 40(3):259-268. https://doi.org/10.1617/s11527-0069104-1

5. Tremblay MH, Lory F, Marchand J, Scherer GW, Valenza JJ (2007) Ability of the glue spall model to account for the deicer salt scaling deterioration of concrete. In: Paper presented at the 12th ICCC Montreal, Canada, July 8-12, 2007

6. Çopuroğlu O, Schlangen E (2008) Modeling of frost salt scaling. Cem Concr Res 38(1):27-39. https://doi.org/10. 1016/j.cemconres.2007.09.003

7. Müller M, Ludwig HM (2017) Salt frost scaling of concrete-effect of glue spalling. In: Paper presented at the concrete 2017, Adelaide, Australia, October 22-25, 2017

8. Lindmark S (1998) Mechanisms of salt frost scaling on portland cement-bound materials: studies and hypothesis. Dissertation, Lunds Universitet, Lund, Sweden

9. Powers TC, Helmuth RA (1953) Theory of volume changes in hardened Portland cement paste during freezing. Proc Highway Res Board 32:285-297

10. Taber S (1930) The mechanics of frost heaving. J Geol 38(4):303-317. https://doi.org/10.1086/623720

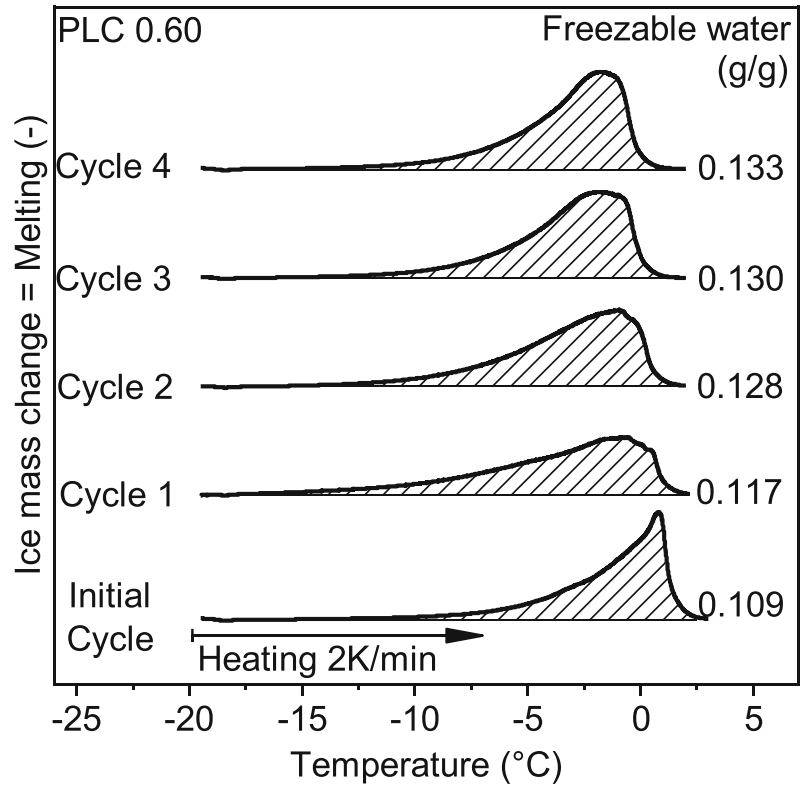

11. Liu Z, Hansen W (2015) A hypothesis for salt frost scaling in cementitious materials. J Adv Concr Technol 13(9):403-414. https://doi.org/10.3151/jact.13.403

12. Gong F, Jacobsen S (2019) Modeling of water transport in highly saturated concrete with wet surface during freeze/ thaw. Cem Concr Res 115:294-307. https://doi.org/10. 1016/j.cemconres.2018.08.013

13. Liu Z (2014) Frost deterioration in concrete due to deicing salt exposure: Mechanism, mitigation and conceptual surface scaling model. Dissertation, University of Michigan, USA

14. Doebelin N, Kleeberg R (2015) Profex: a graphical user interface for the Rietveld refinement program BGMN. J Appl Crystallogr 48:1573-1580. https://doi.org/10.1107/ S1600576715014685

15. Bodnar RJ (1993) Revised equation and table for determining the freezing point depression of $\mathrm{H}_{2} \mathrm{O}-\mathrm{NaCl}$ solutions. Geochim Cosmochim Acta 57(3):683-684. https:// doi.org/10.1016/0016-7037(93)90378-A

16. Washburn EW (1921) The dynamics of capillary flow. Phys Rev 17(3):273-283. https://doi.org/10.1103/PhysRev.17. 273

17. Sant G, Bentz D, Weiss J (2011) Capillary porosity depercolation in cement-based materials: measurement techniques and factors which influence their interpretation. Cem Concr Res 41(8):854-864. https://doi.org/10.1016/j. cemconres.2011.04.006

18. Sun Z, Scherer GW (2010) Pore size and shape in mortar by thermoporometry. Cem Concr Res 40(5):740-751. https:// doi.org/10.1016/j.cemconres.2009.11.011

19. Tunstall LE (2016) A study of surfactant interaction in cement-based systems and the role of the surfactants in frost protection. Dissertation, Princeton University, USA 
20. Fukuta N (1963) Ice nucleation by metaldehyde. Nature 199(4892):475-476. https://doi.org/10.1038/199475a0

21. Johannesson B (2010) Dimensional and ice content changes of hardened concrete at different freezing and thawing temperatures. Cem Concr Compos 32(1):73-83. https://doi. org/10.1016/j.cemconcomp.2009.09.001

22. Wu M, Johannesson B, Geiker M (2014) Determination of ice content in hardened concrete by low-temperature calorimetry: influence of baseline calculation and heat of fusion of confined water. $\mathbf{J}$ Therm Anal Calorim 115(2):1335-1351. https://doi.org/10.1007/s10973-0133520-6

23. Randall M (1930) International critical tables, V-VII. McGraw-Hill, New York

24. Ishikiriyama K, Todoki M (1995) Evaluation of water in silica pores using differential scanning calorimetry. Thermochim Acta 256(2):213-226. https://doi.org/10.1016/ 0040-6031(94)02174-M

25. Mrevlishvili GM, Privalov PL (1968) Calorimetric study of the melting of frozen aqueous solutions of electrolytes. J Struct Chem 9(1):5-7. https://doi.org/10.1007/ bf00744016

26. Andrade C (1993) Calculation of chloride diffusion coefficients in concrete from ionic migration measurements. Cem Concr Res 23(3):724-742. https://doi.org/10.1016/00088846(93)90023-3

27. Locher FW, Wischers G (1974) Aufbau und Eigenschaften des Zementsteins. In: Zement-Taschenbuch. Verein deutscher Zementwerke, pp 45-60

28. Richardson IG (1999) Nature of C-S-H in hardened cements. Cem Concr Res 29(8):1131-1147. https://doi.org/ 10.1016/S0008-8846(99)00168-4

29. Ludwig H-M (2000) Eigenschaften von Betonen mit Portlandhüttenzementen. In: 14, Internationale Baustofftagung-ibausil, Weimar. F.A. Finger-Institut für Baustoffkunde, Bauhaus-Universität Weimar, Weimar, Germany, pp 1141-1157
30. Hawkins P, Tennis PD, Detwiler RJ (2003) The use of limestone in Portland cement: a state-of-the-art review. Portland Cement Association, Skokie

31. Ipavec A, Vuk T, Gabrovšek R, Kaučič V (2013) Chloride binding into hydrated blended cements: the influence of limestone and alkalinity. Cem Concr Res 48:74-85. https:// doi.org/10.1016/j.cemconres.2013.02.010

32. Arya C, Xu Y (1995) Effect of cement type on chloride binding and corrosion of steel in concrete. Cem Concr Res 25(4):893-902. 8846(95)00080-V

33. Brown PW, Doerr A (2000) Chemical changes in concrete due to the ingress of aggressive species. Cem Concr Res 30(3):411-418. https://doi.org/10.1016/S00088846(99)00266-5

34. Shi Z, Geiker MR, Lothenbach B, De Weerdt K, Garzón SF, Enemark-Rasmussen K, Skibsted J (2017) Friedel's salt profiles from thermogravimetric analysis and thermodynamic modelling of Portland cement-based mortars exposed to sodium chloride solution. Cement Concr Compos 78:73-83. https://doi.org/10.1016/j.cemconcomp.2017.01. 002

35. Florea M, Brouwers HJH (2012) Chloride binding related to hydration products: part i: ordinary Portland cement. Cem Concr Res 42:282-290. https://doi.org/10.1016/j. cemconres.2011.09.016

36. Luping T, Nilsson L-O (1993) Chloride binding capacity and binding isotherms of OPC pastes and mortars. Cem Concr Res 23(2):247-253. https://doi.org/10.1016/00088846(93)90089-R

37. Ogirigbo OR, Black L (2017) Chloride binding and diffusion in slag blends: influence of slag composition and temperature. Constr Build Mater 149:816-825. https://doi. org/10.1016/j.conbuildmat.2017.05.184

Publisher's Note Springer Nature remains neutral with regard to jurisdictional claims in published maps and institutional affiliations. 